\title{
Acute myocardial infarction in COVID-19 patients. A review of cases in the literature
}

Nomesh Kumar ${ }^{1}$, Renuka Verma ${ }^{2}$, Petras Lohana ${ }^{1}$, Arti Lohana ${ }^{1}$, Kamleshun Ramphul $^{3}$

${ }^{1}$ Department of Internal Medicine, Liaquat University of Medical and Health Sciences Hospital, Jamshoro, Pakistan

2Department of Internal Medicine, Guru Gobind Singh Medical College and Hospital, Punjab, India

${ }^{3}$ Department of Pediatrics, Shanghai Xin Hua Hospital, Shanghai Jiao Tong University School of Medicine, Shanghai, China

Submitted: 28 July 2021

Accepted: 31 August 2021

Arch Med Sci Atheroscler Dis 2021; 6: e169-e175

DOI: https://doi.org/10.5114/amsad.2021.109287

Copyright @ 2021 Termedia \& Banach

\section{Abstract}

Introduction: COVID-19 is an ongoing pandemic that has lasted more than a year. Patients with multiple comorbidities such as diabetes, hypertension, and smoking have been shown to be at increased risk of a more severe course and lethal outcome. Since the disease can also lead to a hypercoagulable state, several cases of acute myocardial infarction (AMI) have also been recorded.

Material and methods: We searched PubMed/Medline for case reports of AMI occurring in COVID-19 positive patients using "acute myocardial infarction", "COVID-19", and "SARS-CoV-2" as keywords.

Results: Thirty-three articles covering 37 patients were identified, among which $30(81.1 \%)$ were male, and $7(18.9 \%)$ were females. The mean age of these 37 patients was $52.8 \pm 15.6$ years. Most cases were from the United States (17 cases, $45.9 \%$ ). Several comorbidities such as hypertension (16 cases, $43.2 \%)$, diabetes (14 cases, $37.8 \%$ ), smoking ( 8 cases, $21.6 \%$ ), obesity ( 3 cases, $8.1 \%$ ), morbid obesity ( 1 case, $2.7 \%$ ), and elevated lipid levels (4 cases, $10.8 \%$ ) were also identified. The most common symptom of AMI was chest tightness ( 22 cases, $59.5 \%$ ), while the most common symptoms for COVID-19 were dyspnoea (25 cases, 67.6\%) and fever (22 cases, 59.5\%). The mortality rate was $35.1 \%$.

Conclusions: Given the high mortality rate, physicians are encouraged to properly check for signs of cardiac dysfunction and possible AMI while treating COVID-19 positive patients with several comorbidities or previous history of AMI.

Key words: ECG changes, case reports, COVID-19, pandemic, acute myocardial infarction, risk factor.

\section{Introduction}

The first cases of coronavirus disease 2019 (COVID-19) occurred in December 2019. The virus continued to spread worldwide and became a pandemic on March $11^{\text {th }}, 2020$ [1]. The infection is caused by severe acute respiratory syndrome coronavirus 2 (SARS-CoV-2), which is a single-stranded RNA virus with an envelope that comes from the Coronaviridae family. This family also includes severe acute respiratory syndrome coronavirus (SARS-CoV) and Middle East respiratory syndrome-related

\author{
Corresponding author: \\ Dr. Petras Lohana MBBS \\ Department of \\ Internal Medicine \\ Liaquat University \\ of Medical and Health \\ Sciences Hospital \\ Jamshoro, Pakistan \\ E-mail: drpetraslohana34@ \\ gmail.com
}


coronavirus (MERS-CoV), which previously led to severe acute respiratory syndromes (SARS) and Middle East respiratory syndrome (MERS) respectively $[1,2]$.

The world slowly learned more about the virus, and found several risk factors such as diabetes, hypertension, advanced age, smoking, chronic obstructive pulmonary disease (COPD), asthma, and past history of cerebrovascular diseases that are believed to provoke worse outcomes of the infection [2-5]. Since COVID-19 is also associated with hypercoagulation and thrombosis, multiple early reports and questions were raised about the likely increased risk of acute myocardial infarction (AMI) developing in patients with risk factors [6]. The pandemic has also severely affected several health care systems and cardiovascular departments in several areas, which may cause a delay and hesitancy for patients with symptoms of AMI to seek appropriate care [7].

We, therefore, aim to perform a review of all cases of AMI published in the literature to identify the major risk factors and suggest possible changes in clinical care that can help improve the outcomes of patients.

\section{Material and methods}

We searched PubMed/Medline from inception to May $30^{\text {th }}, 2021$ for cases of AMI using the keywords "acute myocardial infarction", "COVID-19", and "SARS-CoV-2". Since several reports were rushed for publication during the early phase of the pandemic as letters, we limited our search criteria to case reports and letters published in English, French, Spanish, and Chinese. Our team was divided into two groups (PL/AL/NK and RV/ $K R$ ) that independently searched and drafted their lists. The two groups then discussed their results, and all differences in choices were solved through thorough discussions.

\section{Statistical analysis}

Analyse-it software (Analyse-it Software Ltd, Leeds, UK, https://analyse-it.com/) and Microsoft Excel (https://www.microsoft.com/en-us/microsoft-365/excel) were used to evaluate the data obtained. We calculated the means with standard deviations of ages and presented several categorical values as percentages as appropriate.

\section{Results}

We found 147 results that fitted our initial search criteria. The authors read all full manuscripts and eventually retained 33 that contained reports from 37 patients (Table I) [8-40]. Thirty $(81.1 \%)$ patients were male while $7(18.9 \%)$ were females. The mean age was 52.8 years, with a standard deviation of 15.6. The youngest patient was 27 years of age, and the oldest was 86 . Eight $(21.6 \%)$ cases were reported within the age range of 27-39 years, 16 (43.2\%) in the range 40-59, and 13 (35.1\%) were 60 or older. Most cases were reported from the United States (17 cases, 45.9\%). Other countries included France, Italy, Japan, South Korea, Pakistan, Qatar, Spain, and the United Kingdom with 2 cases each and Iran, Portugal, Saudi Arabia, and Switzerland with one case each.

Several comorbidities were also listed among the cases. Sixteen (43.2\%) patients had a history of hypertension, $14(37.8 \%)$ had diabetes, $8(21.6 \%)$ were smokers, 3 (8.1\%) were obese, $1(2.7 \%)$ was morbidly obese, and 4 (10.8\%) had elevated lipid levels. Six (16.2\%) patients were also reported to have a previous history of $\mathrm{MI}$, and 2 patients had a history of stroke in the past. The time of presentation and diagnosis of AMI relative to the symptoms or diagnosis of COVID-19 varied a lot. Some patients were diagnosed with COVID-19 only after they were admitted for symptoms of AMI, while some cases of AMI occurred during their admission for COVID-19. There were also some severe cases of COVID-19 in which a diagnosis was made as a routine check while the patient was sedated or on ventilation. Twenty-two (59.5\%) patients reported symptoms of chest pain or tightness. Twenty-five (67.6\%) patients had findings of dyspnoea. However, shortness of breath can be seen in both COVID-19 patients and in AMI patients. Among the main COVID-19 symptoms, 22 (59.5\%) patients had fever, 20 (54.1\%) had cough, 1 (2.7\%) reported gastrointestinal symptoms, and 16 (43.2\%) were entirely asymptomatic. All 38 cases had positive ECG changes, with 3 cases presenting with non-ST elevation myocardial infarction (NSTEMI), 29 with ST elevation myocardial infarction (STEMI), and 1 case presented initially with NSTEMI which turned into STEMI.

Unfortunately, 13 (35.1\%) patients died during their hospitalization. The mean age of those who died was 54.9 years, with a standard deviation of 14.6 years. Eleven (84.6\%) were male, and $2(15.4 \%)$ were female. Seven $(53.8 \%)$ of them had a history of hypertension, and 6 (46.2\%) had diabetes. One of them $(7.7 \%)$ had a previous history of $\mathrm{MI}$, and $1(7.7 \%)$ also had a stroke in the past. Three $(23.1 \%)$ patients who died had a history of smoking. The majority of cases (5 cases, $38.5 \%$ ) were from the United States.

\section{Discussions}

Our findings highlight several important points that can help address the care and prevention of AMI among patients with COVID-19. The higher incidence of cases of AMI in males compared to females has also been reported among non- 


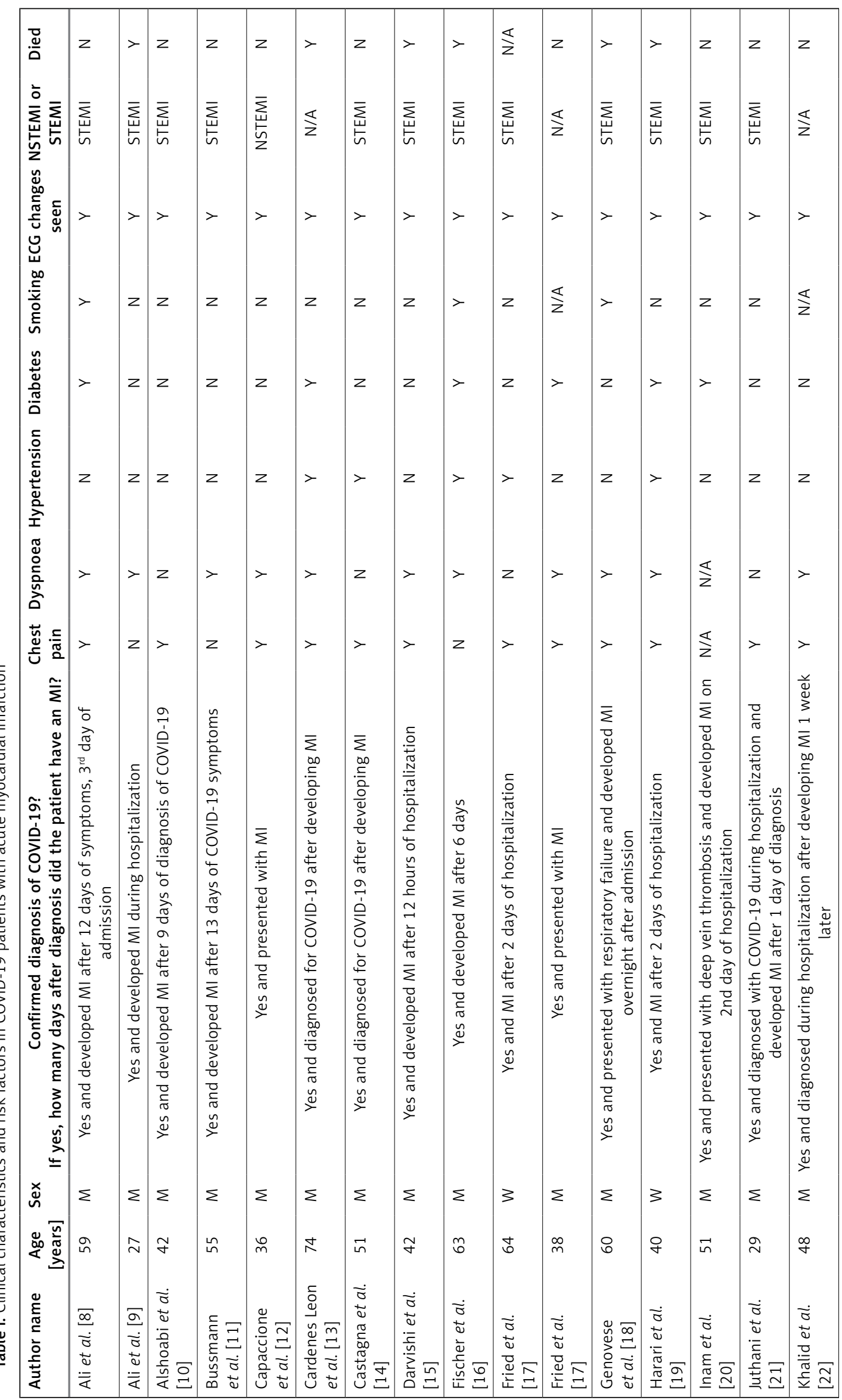




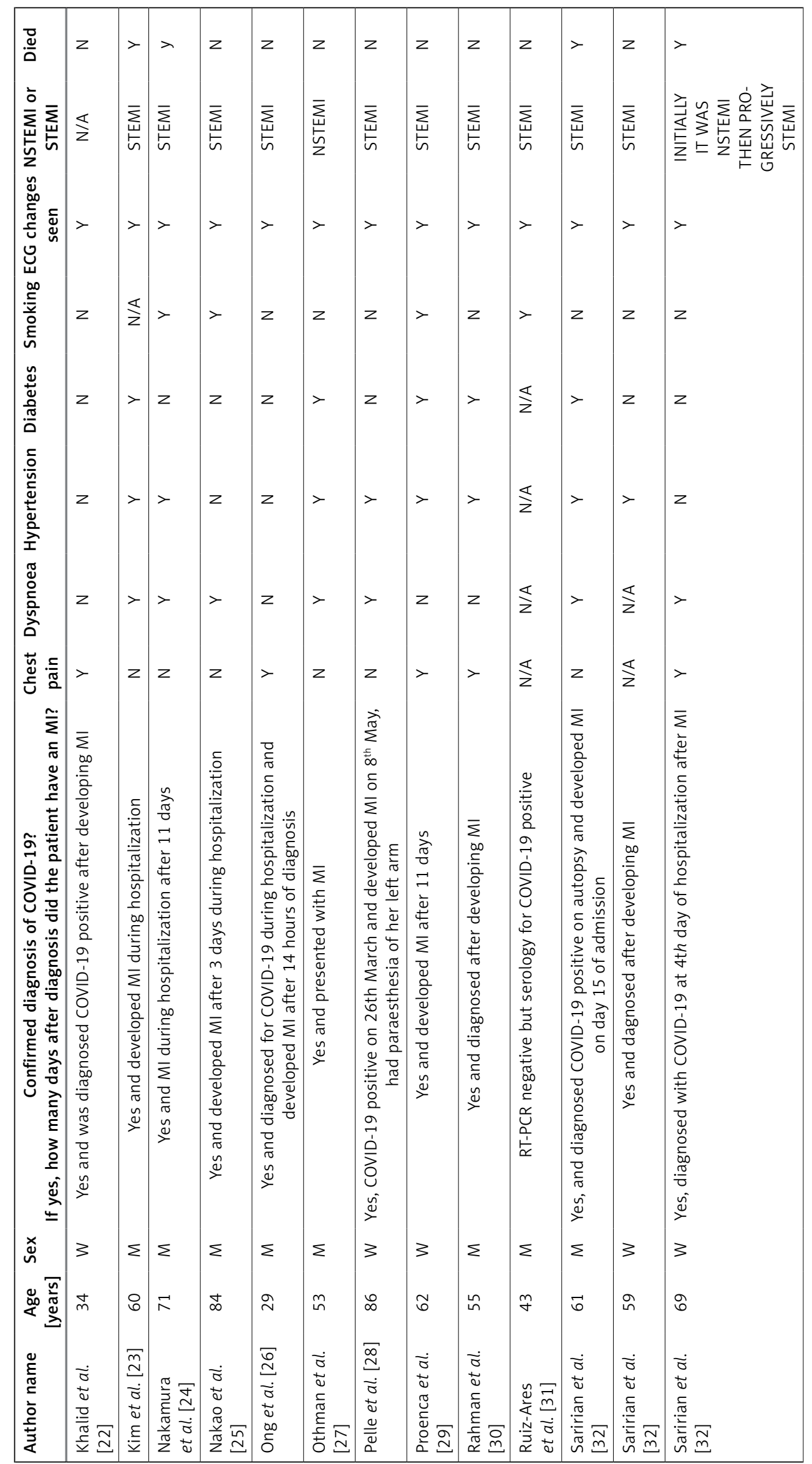




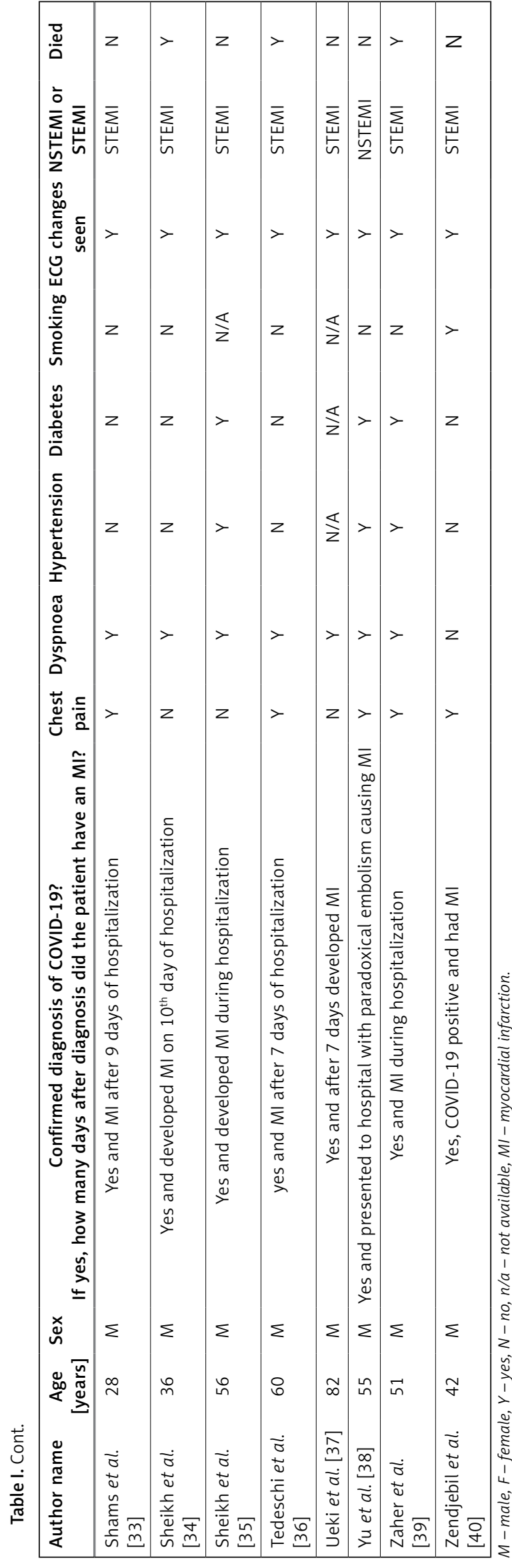

COVID-19 patients [41]. The incidence of hypertension, diabetes, and smoking was higher in the group of patients who died than in those who survived. Several theories have hypothesized that patients with COVID-19 may have a higher risk of thrombosis and thrombotic events or complications, and smoking, hypertension and diabetes may further worsen their prognosis $[2,4,5$, 42-46]. The infection can cause a rise in several cytokines and D-dimer level which leads to an elevated prothrombin time. It can also cause endothelial damage, which predisposes the patient to a hypercoagulable state [47]. Schoenhagen et al. also suggested that these changes may cause plaques to weaken and rupture, and thus cause coronary thrombosis [48]. The mortality rate observed in our study is lower than in the results reported by Bangalore et al. (72\%) at their centre. However, we believe a larger sample size may help to provide greater predictive power eventually. Moreover, since antiplatelets and anticoagulation therapy might be helpful in preventing acute myocardial infarction, the role should be considered and further explored in at-risk patients such as those with multiple comorbid conditions but not already on therapy and admitted with severe COVID-19 [49]. In their analysis, Godino et al. suggested that the indications for such therapies should be evaluated based on the patient's clinical findings and also the severity of their disease [50]. The incidence of additional conditions related to COVID-19 such as findings of acute myocarditis, pulmonary embolism, and acute respiratory distress syndrome can also be studied and compared to understand the impact and protective role of such therapies in such scenarios [51-54].

Several changes in protocol and care can be encouraged to lower the occurrence and mortality among COVID-19 patients with an AMI episode. Patients who are at risk and have several comorbidities should have an ECG on admission, and it should be repeated as appropriate depending on their clinical findings. Our study also showed that while chest pain was very common, it can easily be missed in sedated patients. Thus, physicians should also include an ECG test and cardiac enzyme test in those groups of patients. Finally, since both COVID-19 and AMI patients may typically have shortness of breath or dyspnoea, further cardiac testing should be considered based on the presentation as well as the comorbidities of the patients. Cardiac imaging such as echo and spiral CT can also be helpful to rule out other possible cardiovascular complications in such at-risk patients. While these changes may be, at first, deemed challenging for several health care systems in developing countries, the proper pre- 
vention and early management and care may ultimately help to improve the survival rates and also the length of stays and burden.

There are some limitations to our study, and proper consideration should be taken when using the results obtained. The sample size was small as we used case reports from the literature, and researchers and physicians are encouraged to report the data from their centres in the future to further study and confirm our findings. Most studies did not provide adequate information on several laboratory values and the level of severity of COVID-19. It was thus not possible for us to subdivide and analyse the results based on the severity of COVID-19. The case reports also did not allow us to properly evaluate the levels of several markers such as D-dimers, and several past medical history or current medical findings may have been omitted by some of the authors. Finally, the case reports did not include any vaccination history of the patients (for COVID-19).

In conclusion, our study showed a high mortality rate among patients who suffer from acute myocardial infection during a positive infection of COVID-19. Males were more at risk than females, and several comorbidities such as hypertension, diabetes, and smoking may participate in the pathophysiology of these patients. We encourage further research to confirm our findings using larger samples from different centres.

\section{Conflict of interest}

The authors declare no conflict of interest.

\section{References}

1. Ramphul K, Mejias SG. Coronavirus disease: a review of a new threat to public health. Cureus 2020; 12: e7276.

2. Ramphul K, Ramphul Y, Park Y, Lohana P, Kaur Dhillon $B$, Sombans S. A comprehensive review and update on severe acute respiratory syndrome coronavirus 2 (SARSCoV-2) and Coronavirus disease 2019 (COVID-19): what do we know now in 2021? Arch Med Sci Atheroscler Dis 2021; 6: 5-13.

3. Del Sole F, Farcomeni A, Loffredo L, Carnevale R, Menichelli D. Features of severe COVID-19: a systematic review and meta-analysis. Eur J Clin Invest 2020; 50: e13378.

4. Lippi G, Sanchis-Gomar F, Henry BM. Active smoking and COVID-19: a double-edged sword. Eur J Intern Med 2020; 77: 123-4

5. Ramphul K, Lohana P, Ramphul Y, et al. Hypertension, diabetes mellitus, and cerebrovascular disease predis pose to a more severe outcome of COVID-19. Arch Med Sci Atheroscler Dis 2021; 6: 30-9.

6. Al-Ani F, Chehade S, Lazo-Langner A. Thrombosis risk associated with COVID-19 infection. A scoping review. Thromb Res 2020; 192: 152-60.

7. Ramphul K, Lohana P, Verma R, Sombans S. The impact of COVID-19 on cardiology departments. Arch Med Sci Atheroscler Dis 2021; 6: e1-2.
8. Ali A, Khattak MF, Khan MW. COVID-19 pneumonia: ST-segment elevation myocardial infarction (STEMI) and myocarditis. Cureus 2020; 12: e11901.

9. Ali M, Mujahid A, Sherani K, Surani S. ST-elevation myocardial infarction in a 27 -year-old male with COVID-19. Cureus 2020; 12: e10384.

10. Alshoabi SA, Haider KH, Mostafa MA, Hamid AM, Daqqaq TS. An unusual and atypical presentation of the novel coronavirus: a case report and brief review of the literature. J Taibah Univ Med Sci 2021.

11. Bussmann BM, Shabbir A, Warwick A, Orr W. Acute coronary artery thrombosis presenting as asymptomatic ST-elevation myocardial infarction in a patient with COVID-19 pneumonia. BMJ Case Rep 2021; 14 : e241856.

12. Capaccione KM, Leb JS, D'Souza B, Utukuri P, Salvatore MM. Acute myocardial infarction secondary to COVID-19 infection: a case report and review of the literature. Clin Imaging 2021; 72: 178-82.

13. Cárdenes León A, Hernández Meneses B, Sánchez Pérez A, Novoa Medina JM, Bujanda Morún PF, Martín Lorenzo P. Acute coronary syndrome and shock in the context of acute COVID-19 infection. Rev Esp Cardiol 2020; 73: 678-9.

14. Castagna F, Cerrud-Rodriguez R, Villela MA, Bortnick AE. SARS-COV-2 infection presenting as ST-elevation myocardial infarction. Catheter Cardiovasc Interv 2021; 97 : e339-42.

15. Darvishi M, Shahali H. Acute cardiac tamponade: a case of life-threatening coronavirus disease 2019 complication during air medical transportation. Air Med J 2021; 40: $179-81$.

16. Fischer Q, Darmon A, Ducrocq G, Feldman L. Case report of anterior ST-elevation myocardial infarction in a patient with coronavirus disease-2019. Eur Heart J Case Rep 2020; 4: 1-5.

17. Fried JA, Ramasubbu K, Bhatt R, et al. The variety of cardiovascular presentations of COVID-19. Circulation 2020; 141: 1930-6.

18. Genovese L, Ruiz D, Tehrani B, Sinha S. Acute coronary thrombosis as a complication of COVID-19. BMJ Case Rep 2021; 14: e238218.

19. Harari R, Bangalore S, Chang E, Shah B. COVID-19 complicated by acute myocardial infarction with extensive thrombus burden and cardiogenic shock. Catheter Cardiovasc Interv 2021; 97: e661-6.

20. Inam F, Singh PR, Khalid F, Javed A, Shah AR. Acute coronary syndrome and COVID-19: a case report of refractory hypercoagulability. Cureus 2021; 13: e13675.

21. Juthani P, Bhojwani R, Gupta N. Coronavirus disease 2019 (COVID-19) manifestation as acute myocardial infarction in a young, healthy male. Case Rep Infect Dis 2020; 2020: 8864985.

22. Khalid N, Chen Y, Case BC, et al. COVID-19 (SARS-CoV-2) and the heart - an ominous association. Cardiovasc Revasc Med 2020; 21: 946-9.

23. Kim HN, Lee JH, Park HS, et al. A case of COVID-19 with acute myocardial infarction and cardiogenic shock. J Korean Med Sci 2020; 35: e258.

24. Nakamura Y, Shimizu M, Yamaki T, et al. Myocardial injury in a patient with severe coronavirus disease: a case report. J Infect Chemother 2021; 27: 364-8.

25. Nakao M, Matsuda J, Iwai M, et al. Coronary spasm and optical coherence tomography defined plaque erosion causing ST-segment-elevation acute myocardial infarction in a patient with COVID-19 pneumonia. J Cardiol Cases 2021; 23: 87-9. 
26. Ong E, Castro-Dominguez Y, Brennan J, Oen-Hsiao J. COVID-19 complicated by ST-segment elevation myocardial infarction in a 29-year-old patient. Catheter Cardiovasc Interv 2021; 97: 267-71.

27. Othman F, Abid AR, Alibrahim M, et al. Non-ST seg ment elevation myocardial infarction in a patient with COVID-19. Heart Views 2020; 21: 215-9.

28. Pelle MC, Tassone B, Ricchio M, et al. Late-onset myocardial infarction and autoimmune haemolytic anaemia in a COVID-19 patient without respiratory symptoms, concomitant with a paradoxical increase in inflammatory markers: a case report. J Med Case Rep 2020; 14: 246.

29. Proença T, Paiva M, Alves Pinto R, Martins Carvalho M, Lopes R, Macedo F. ST-elevation acute coronary syndrome without obstructive coronary disease in a COVID-19 patient. Rev Port Cardiol 2021; 40: 69-70.

30. Rahman T, Alayo QA, Chaudhary SG, et al. STEMI associated with SARS-CoV-2 infection and the use of ECMO as a potential therapeutic approach in addition to the $\mathrm{PCl}$. Oxf Med Case Reports 2021; 2021: omaa148.

31. Ruiz-Ares G, Jimenez-Valero S, Fernández-Prieto A, et al. Concurrent stroke and myocardial infarction after mild COVID-19 infection. Neurologist 2021; 26: 86-9.

32. Saririan M, Armstrong R, George JC, et al. ST-segment elevation in patients presenting with COVID-19: case series. Eur Heart J Case Rep 2021; 5: ytaa553.

33. Shams A, Ata F, Mushtaq K, Munir W, Yousaf Z. Coronary thrombosis in a young male with COVID-19. IDCases 2020; 21: e00923.

34. Sheikh AB, ljaz Z, Javed N, Upadyay S, Shekhar R. COVID-19 with non-obstructive coronary artery disease in a young adult. J Community Hosp Intern Med Perspect 2021; 11: 111-4.

35. Sheikh AB, Shekhar R, Javed N, Upadhyay S. Inferior wall myocardial infarction in severe COVID-19 infection: a case report. Am J Case Rep 2020; 21: e926101.

36. Tedeschi D, Rizzi A, Biscaglia S, Tumscitz C. Acute myocardial infarction and large coronary thrombosis in a patient with COVID-19. Catheter Cardiovasc Interv 2021; 97: 272-7.

37. Ueki Y, Otsuka T, Windecker S, Räber L. ST-elevation myocardial infarction and pulmonary embolism in a patient with COVID-19 acute respiratory distress syndrome. Eur Heart J 2020; 41: 2134

38. Yu MD, Desai N, Sanagala T, Darki A. Paradoxical embolism causing myocardial infarction in a COVID-19 patient presenting with pulmonary embolism. Cureus 2021; 13: e13975.

39. Zaher N, Sattar Y, Mahmood S, Vacek T, Alraies MC. COVID-19 infection complicated by a complete occlusion of the left circumflex artery with acute restenosis after drug-eluting stent placement. Cureus 2020; 12: e10708.

40. Zendjebil S, Zeitouni M, Batonga $M$, et al. Acute multivessel coronary occlusion revealing COVID-19 in a young adult. JACC Case Rep 2020; 2: 1297-301.

41. Ramphul K, Ramphul Y, Sombans S, Lohana P, Joynauth J. Acute myocardial infarction admissions among young adults in the United States: an update on the incidence and burden. Arch Med Sci Atheroscler Dis 2021; 6: e18-20.

42. Adeli K, Lippi G, Henry BM, Sanchis-Gomar F, Mattiuzzi C. Updates on laboratory investigations in coronavirus disease 2019 (COVID-19). Clin Chem Lab Med 2020; 91: e2020030.

43. Henry BM, de Oliveira MHS, Benoit S, Plebani M, Lippi G. Hematologic, biochemical and immune biomarker ab- normalities associated with severe illness and mortality in coronavirus disease 2019 (COVID-19): a meta-analysis. Clin Chem Lab Med 2020; 58: 1021-8.

44. Lippi G, Plebani M. Procalcitonin in patients with severe coronavirus disease 2019 (COVID-19): a meta-analysis. Clin Chim Acta 2020; 505: 190-1.

45. Lippi G, Plebani M. Laboratory abnormalities in patients with COVID-2019 infection. Clin Chem Lab Med 2020; 58: 1131-4.

46. Ramphul K, Mejias SG, Ramphul Y. Headache may not be linked with severity of coronavirus disease 2019 (COVID-19). World J Emerg Med 2020; 11: 274.

47. Cardiac Manifestations Of Coronavirus (COVID-19). Available at: https://www.statpearls.com/articlelibrary/ viewarticle/95199/?utm_source=pubmed\&utm_campaign $=$ CME\&utm content $=95199$, Accessed date: 10 June 2021.

48. Schoenhagen P, Tuzcu EM, Ellis SG. Plaque vulnerability, plaque rupture, and acute coronary syndromes: (multi)-focal manifestation of a systemic disease process. Circulation 2002; 106: 760-2.

49. Watson RA, Johnson DM, Dharia RN, Merli GJ, Doherty JU. Anti-coagulant and anti-platelet therapy in the COVID-19 patient: a best practices quality initiative across a large health system. Hospital Practice 2020; 48: 169-79.

50. Godino C, Scotti A, Maugeri N, et al. Antithrombotic therapy in patients with COVID-19? -Rationale and Evidence. Int J Cardiol 2021; 324: 261-6.

51. Nishiga M, Wang DW, Han Y, Lewis DB, Wu JC. COVID-19 and cardiovascular disease: from basic mechanisms to clinical perspectives. Nature Rev Cardiol 2020; 17: 54358.

52. Long B, Brady WJ, Koyfman A, Gottlieb M. Cardiovascular complications in COVID-19. Am J Emergency Med 2020; 38: 1504-7.

53. Chang WT, Toh HS, Liao CT, Yu WL. Cardiac involvement of COVID-19: a comprehensive review. Am J Med Sci 2021; 361: 14-22.

54. Lang JP, Wang X, Moura FA, Siddiqi HK, Morrow DA, Bohula EA. A current review of COVID-19 for the cardiovascular specialist. Am Heart J 2020; 226: 29-44. 